\title{
The EMT activator ZEB1 promotes tumor growth and determines differential response to chemotherapy in mantle cell lymphoma
}

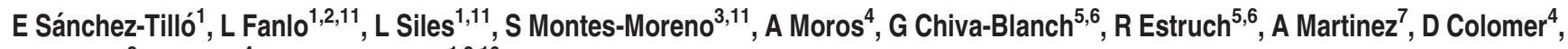 \\ B Györffy ${ }^{8}$, G Roué $^{4}$ and A Postigo ${ }^{\star, 1,9,10}$
}

Mantle cell lymphoma (MCL) is a B-cell malignancy characterized by a poor response to treatment and prognosis. Constitutive activation of different signaling pathways in subsets of MCLs, through genetic and/or nongenetic alterations, endows tumor cells with enhanced proliferation and reduced apoptosis. The canonical Wnt pathway ( $\beta$-catenin/TCF-LEF), implicated in the pathogenesis of numerous cancers, is constitutively active in half of MCLs. Here, we show that ZEB1, a transcription factor better known for promoting metastasis in carcinomas, is expressed in primary MCLs with active Wnt signaling. ZEB1 expression in MCL cells depends on Wnt, being downregulated by $\beta$-catenin knockdown or blocking of Wnt signaling by salinomycin. Knockdown of ZEB1 reduces in vitro cell viability and proliferation in MCL cells, and, importantly, tumor growth in mouse xenograft models. ZEB1 activates proliferation-associated (HMGB2, UHRF1, CENPF, MYC, MKI67, and CCND1) and antiapoptotic (MCL1, BCL2, and BIRC5) genes and inhibits pro-apoptotic ones (TP53, BBC3, PMAIP1, and BAX). We show that ZEB1 expression in MCL cells determines differential resistance to chemotherapy drugs and regulates transporters involved in drug influx/efflux. Downregulation of ZEB1 by salinomycin increases the sensitivity of MCL cells to the cytotoxic effect of doxorubicin, cytarabine and gemcitabine. Lastly, salinomycin and doxorubicin display a synergistic effect in established and primary MCL cells. These results identify ZEB1 in MCL where it promotes cell proliferation, enhanced tumor growth and a differential response to chemotherapy drugs. ZEB1 could thus potentially become a predictive biomarker and therapeutic target in this lymphoma. Cell Death and Differentiation (2014) 21, 247-257; doi:10.1038/cdd.2013.123; published online 6 September 2013

Mantle cell lymphomas (MCLs) are characterized by a poor response to chemotherapy, frequent relapse and the worst prognosis among B-cell lymphomas. ${ }^{1} \mathrm{MCLs}$ derive from naive $B$ cells displaying a mature phenotype similar to those in the mantle zone of lymph node follicles. Evidence at multiple levels indicates that MCL is a more heterogeneous entity than previously thought. ${ }^{1}$

The genetic hallmark of MCLs is the $t(11 ; 14)(q 13 ; q 32)$ translocation of cyclin D1 to the Ig heavy chain enhancer. However, cyclin D1 overexpression is not sufficient to induce $\mathrm{MCL}$ in mice, its knockdown has limited effect on the proliferation or apoptosis of MCL cells and cyclin D1-negative cases have also been identified. ${ }^{1,2}$ Clinical, pathological and ontogenic heterogeneity among subsets of MCLs reflect the involvement of additional signals in the genesis and evolution of this lymphoma. In that regard, chromosomal alterations and nongenetic modifications resulting in the constitutive activation of pro-oncogenic signals (for example, NF- $\kappa \mathrm{B}$, Notch, PI3K/AKT/mTOR, and Wnt) and/or deregulation of DNA repair and apoptotic pathways and genes (for example, $A K T, B C L 2, M C L 1$ ) have been found in subsets of MCLs, providing additional levels of plasticity in the genesis and progression of the disease. .,3-11 $^{1,}$

Of particular interest is the canonical Wnt pathway that has a crucial role in normal hematopoiesis and whose aberrant activation, long known to drive tumorigenesis in solid tumors, has also been involved in a number of hematological malignancies, including MCLs. ${ }^{3,5,6,12-19,20}$ In addition to gain-of-function mutations of intracellular components of the Wnt pathway, overexpression of Wnt receptors and ligands or downregulation of Wnt inhibitors through nongenetic modifications are also common. ${ }^{3,5-7,21}$

Short-lived response and development of resistance to first-line immunochemotherapy are major challenges in MCL

\footnotetext{
${ }^{1}$ Group of Transcriptional Regulation of Gene Expression, Department of Oncology and Hematology, IDIBAPS, CIBERehd, Barcelona 08036, Spain; ${ }^{2}$ Master Program in Biomedical Research, University Pompeu Fabra, Barcelona 08002, Spain; ${ }^{3}$ Department of Pathology and Group of Cancer Genomics, Hospital Marques de Valdecilla, IFIMAV, Santander 39008, Spain; ${ }^{4}$ Hematopathology Unit, Hospital Clinic, IDIBAPS, Barcelona 08036, Spain; ${ }^{5}$ Department of Internal Medicine, Hospital Clinic, Barcelona 08036, Spain; ${ }^{6}$ CIBERobn, ISCIII, Santiago de Compostela 15706, Spain; ${ }^{7}$ Department of Pathology, Hospital Clinic, Barcelona 08036, Spain; ${ }^{8}$ Research Lab for Pediatrics and Nephrology, Hungarian Academy of Sciences, Semmelweis University, 1st Department of Pediatrics, Budapest 1083, Hungary; ${ }^{9} \mathrm{James}$ Graham Brown Cancer Center, Louisville, KY 40202, USA and ${ }^{10}$ ICREA, Barcelona 08010, Spain

${ }^{*}$ Corresponding author: A Postigo, Group of Transcriptional Regulation of Gene Expression, IDIBAPS, Casanova 143, Barcelona 08036, Spain. Fax: +34 93 0451 527; E-mail: idib412@clinic.ub.es

${ }^{11}$ These authors contributed equally to this work.

Keywords: ZEB1; mantle cell lymphoma; transcription; Wnt signaling

Abbreviations: ChIP, chromatin immunoprecipitation; Cl, combination index; EMT, epithelial-to-mesenquimal transition; LMB, leptomycin B; MCL, mantle cell lymphoma; qRT-PCR, quantitative real-time PCR; TMA, tissue microarray

Received 23.2.13; revised 19.7.13; accepted 02.8.13; Edited by JP Medema; published online 06.9.2013
} 
and new therapeutic strategies are being developed. ${ }^{1,22,23}$ Constitutive Wnt signaling associates to increased cellular proliferation and higher resistance to apoptosis and chemotherapy in subsets of leukemias and lymphomas and established cell lines derived from them, including MCLs. ${ }^{3,5,6,13,15-20}$ In turn, inhibitors of Wnt pathway induce cytotoxicity in leukemia and lymphoma cells. 5,16,17 The characterization in MCLs of a subpopulation of stem-like cells retaining the capacity for tumor initiation could help explaining relapses and also offers new avenues in MCL treatment. ${ }^{24}$ High-throughput screenings have identified drugs preferentially targeting stem-like cancer cells with some, like salinomycin, interfering Wnt signaling. ${ }^{16,25}$

Canonical Wnt signaling is triggered by the engagement of cell surface receptors with soluble ligands prompting accumulation of the oncoprotein $\beta$-catenin. At the nucleus, $\beta$-catenin complexes with TCF-LEF transcription factors to transcriptionally activate Wnt target genes. ${ }^{20,26}$ In solid tumors, $\beta$-catenin colocalizes with the transcription factor ZEB1 in the nuclei of undifferentiated cancer cells at the invasive front. ${ }^{27-31}$ Depending on the target gene, ZEB1 could function as either a transcriptional repressor or an activator through the recruitment of different cofactors. ${ }^{29,32-35}$ In malignant epithelial cells, ZEB1 triggers an epithelial-tomesenchymal transition (EMT), a process by which cancer cells acquire a pro-invasive phenotype. ${ }^{36,37}$ Consequently, in solid cancers, ZEB1 promotes tumor invasiveness and metastasis and correlates with poorer clinical prognosis. ${ }^{38,39}$ However, the expression and role of ZEB1 in MCL remains unexplored.

In this study, we show that ZEB1 is expressed in about half of MCLs where it correlates with $\beta$-catenin. ZEB1 expression in MCL cells is dependent on Wnt signaling, being upregulated by further activation of the Wnt pathway and downregulated by the knockdown of $\beta$-catenin or treatment with salinomycin, which we show here blocks the binding of $\beta$-catenin/TCF4 complexes onto the ZEB1 promoter. ZEB1 expression promotes enhanced proliferation in vitro and in vivo. Thus, ZEB1 knockdown reduces cell viability and proliferation in MCL cells and tumor growth in mouse xenograft models. ZEB1 expression activates the expression of anti-apoptotic (MCL1, BCL2, and BIRC5) and proliferation-associated (HMGB2, UHRF1, CENPF, MYC, MKI67, and CCND1) genes and represses the apoptotic ones (TP53, BBC3, PMAIP1, and $B A X)$. ZEB1 modulates the expression of cell-membrane transporters that control the influx and efflux of chemotherapy drugs used in MCL and determines differential response to their cytotoxic effects. Thus, ZEB1 expression increases the in vitro resistance of MCL cells to doxorubicin, cytarabine and gemcitabine but not to vincristine. In an MCL xenograft murine model, reduction in tumor growth by treatment with doxorubicin was enhanced by the knockdown of ZEB1 expression. Interestingly, salinomycin enhances the sensitivity of MCL cells to doxorubicin, cytarabine and gemcitabine. Lastly, salinomycin and doxorubicin display a synergistic cytotoxic effect in established MCL cell lines and primary MCL cells.

Altogether, these results set ZEB1 as a new biomarker in MCLs, where it determines enhanced cell proliferation and resistance to apoptosis and, ultimately, MCL tumor growth.

\section{Results}

ZEB1 is expressed in primary cases of MCL with active Wnt signaling. Aberrant activation of the Wnt pathway and expression of $\beta$-catenin occurs in about half of primary MCL cases. ${ }^{5,8}$ Gene expression profile studies also revealed the upregulation of Wnt ligands, their receptors and/or Wnt downstream targets in primary MCLs. ${ }^{3,5,6,8}$ In carcinomas, ZEB1 coexpresses with $\beta$-catenin in undifferentiated tumor cells at their leading front, promoting invasiveness and metastasis. $^{27-31}$ We therefore decided to examine ZEB1 expression in a tissue microarray (TMA) of MCLs. ZEB1 was expressed in $50.0 \%$ of the cases for about $43.4 \%$ that were positive for $\beta$-catenin (Figure 1), (Supplementary Figures $\mathrm{S} 1 \mathrm{~A}$ and $\mathrm{S} 1 \mathrm{~B})$. Interestingly, there was a high correlation between the expression of both proteins as nuclear ZEB1 was positive in MCL cases expressing nuclear $\beta$-catenin (Wnt active) and absent in MCL cases, where there was no $\beta$-catenin (Wnt inactive; Table 1). Correlation between $\beta$-catenin and ZEB1 suggested that Wnt signaling may regulate ZEB1 in MCLs.

We next examined whether ZEB1 expression associates to prognosis in MCLs. Our analysis of two separate $\mathrm{MCL}$ microarrays data sets ${ }^{40,41}$ revealed that MCL cases with the highest expression of ZEB1 correlated with shorter overall survival (Figures $1 b$ and $c$ ).

Wnt signaling induces ZEB1 expression in MCL cells. Although only about half of primary MCLs display aberrant activation of Wnt, all of the established MCL cell lines reported in the literature have constitutively active Wnt signalings. ${ }^{5}$ We examined the potential regulation of ZEB1 by Wnt in two well-established and widely used MCL cell lines, namely, Granta-519 and Jeko-1 cells, which harbor nuclear expression of $\beta$-catenin (Gelebart et al. ${ }^{5}$ and Supplementary Figure S2A). In line with our results in the TMA, we found that both cell lines also expressed ZEB1 (Supplementary Figure S2B).

Next, we manipulated Wnt signaling to ascertain whether ZEB1 expression in MCL cells is indeed dependent on this pathway. Incubation of MCL cells with either leptomycin B (LMB) - a drug that triggers Wnt signaling ${ }^{30,42}$ - or, more dramatically, with conditioned medium containing Wnt3a (Wnt3a-cm), but not control medium (Ctl-cm), increased basal levels of both $\beta$-catenin and ZEB1 (Figures $2 a$ and $b$ ). The ability of Wnt3a-cm to activate canonical Wnt signaling in MCL cells was confirmed by the increased transcriptional activity of the TOPFLASH reporter, containing multimerized TCF/LEF-binding sites and commonly utilized to assess Wnt signaling $^{26}$ (Supplementary Figure S2C).

On the other hand, we also investigated the effect on ZEB1 of inhibiting the Wnt pathway. We found that knockdown of $\beta$-catenin in MCL cells resulted in lower ZEB1 mRNA and protein levels (Figures $2 c$ and d). We also interfered canonical Wnt signaling in MCL cells with salinomycin, a drug that preferentially targets undifferentiated cancer cells of epithelial and leukemic origin. ${ }^{16,25}$ As shown in Figures $3 a$ and b, treatment of $\mathrm{MCL}$ cells with salinomycin downregulated ZEB1 and $\beta$-catenin at both protein and mRNA levels (Figures $3 a$ and b). 
a
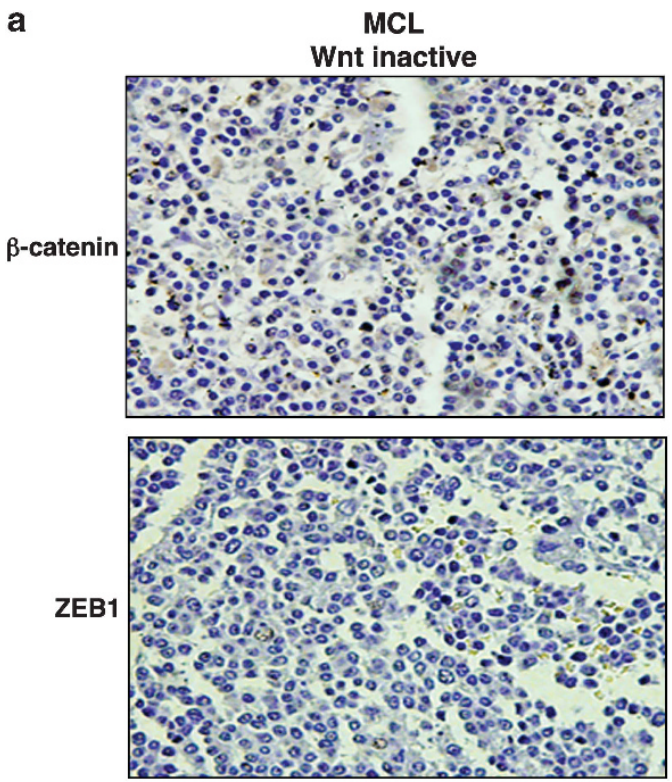

b

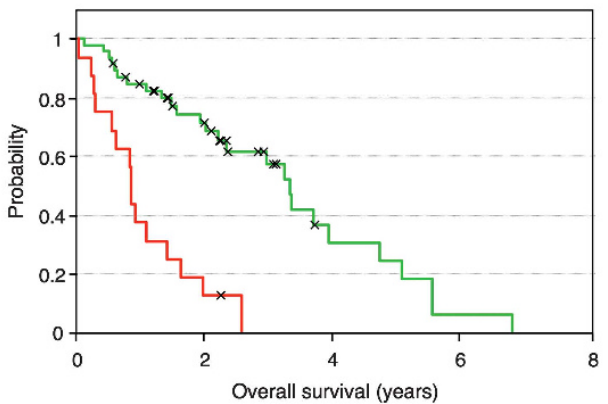

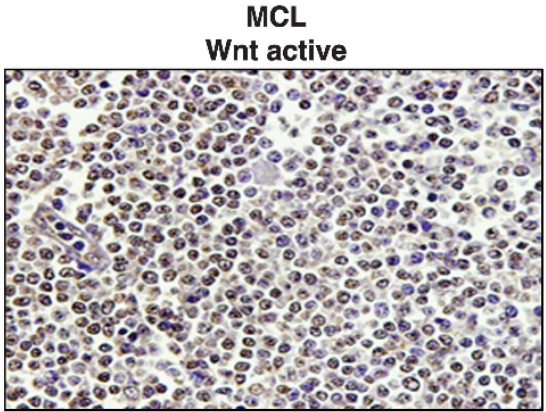
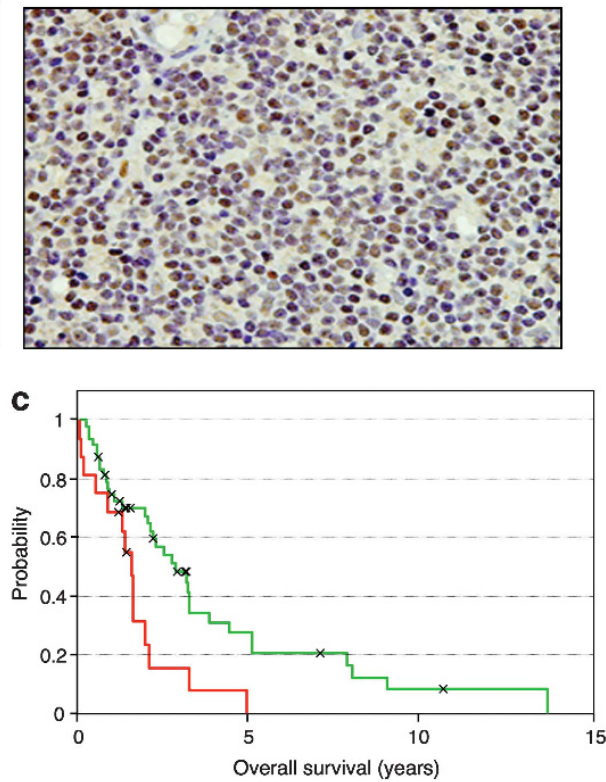

Figure 1 ZEB1 is expressed in MCL and correlates with $\beta$-catenin. Staining of representative MCL samples positive and negative for $\beta$-catenin. Paraffin-embedded sections of a TMA of MCLs were examined by immunohistochemistry for $\beta$-catenin (C2206, same results for clone 14) or ZEB1 (Zfhep, same results for H-102) as described in Supplementary Information. Magnification, $\times 400$. (b) Higher ZEB1 expression associates to poorer prognosis. Kaplan Meier survival plot of MCL patients from the gene microarray in Blenk et al. ${ }^{41}$ according to their level of expression. Patients with the highest expression of ZEB1 (cutoff: upper quartile, red line) had shorter survival than those patients with lower ZEB1 expression (second, third and fourth quartiles, green line). $n=63$, Hazard rate $=5.3, P=7.7 \times 10^{-7}$. (c) As in $\mathbf{b}$, but using the gene microarray data set of Rosenwald et al. ${ }^{40} n=64$, Hazard rate $=2.38 ; P=0.0075$

Table 1 Correlation between ZEB1 and $\beta$-catenin in MCL

\begin{tabular}{|c|c|c|c|}
\hline & & & ZEB1 \\
\hline Spearman's $\rho$ & $\beta$-catenin & $\begin{array}{c}\text { Correlation coefficient } \\
\text { Significance (two-tailed) } \\
n\end{array}$ & $\begin{array}{c}\rho=0.781 \\
P<0.001 \\
46\end{array}$ \\
\hline
\end{tabular}

The human ZEB1 promoter contains two consensusbinding sites for TCF-LEF factors within its first kilobase, at positions -578 and $-161 \mathrm{bp}$. The binding of endogenous $\beta$-catenin/TCF-LEF complexes to these sites in MCL cells was confirmed through chromatin immunoprecipitation (ChIP) assays. In MCL cells, antibodies against $\beta$-catenin and TCF4, but not their respective control IgG, immunoprecipitated regions of the ZEB1 promoter containing both TCF-LEFbinding sites (Figure $3 \mathrm{c}$ ). These antibodies failed to immunoprecipitate a fragment of the GAPDH promoter, which lacks TCF-LEF-binding sites (Figure 3c). We detected binding of RNA polymerase II (Pol II), used as positive control, to the
GAPDH promoter. Figure 3a above shows that salinomycin inhibits $\beta$-catenin expression. Therefore, we next investigated whether inhibition of ZEB1 expression by salinomycin in MCL cells involves, at least in part, reduced binding of $\beta$-catenin and TCF-LEF to the ZEB1 promoter. As shown in Figure 3c, exposure of MCL cells to salinomycin inhibited binding of both $\beta$-catenin and TCF4 to the ZEB1 promoter but did not alter binding of RNA Pol II to the GAPDH promoter.

Salinomycin not only repressed the activity of the TOPFLASH reporter (Lu et al. ${ }^{16}$ and Supplementary Figure S2D) but also inhibited the basal transcriptional activity of the ZEB1 promoter (Figure 3d). Mutation of the TCF-LEF sites at -578 and $-161 \mathrm{bp}$ reverted to large extent the repressor effect of salinomycin on ZEB1 transcriptional activity (Figure 3d). Along with ChIP experiments, Figure 3d suggests that inhibition of ZEB1 by salinomycin requires of intact TCF-LEF sites in its promoter. Altogether, these results demonstrate that ZEB1 expression in MCL cells is dependent on Wnt signaling and can be targeted by salinomycin. 
a
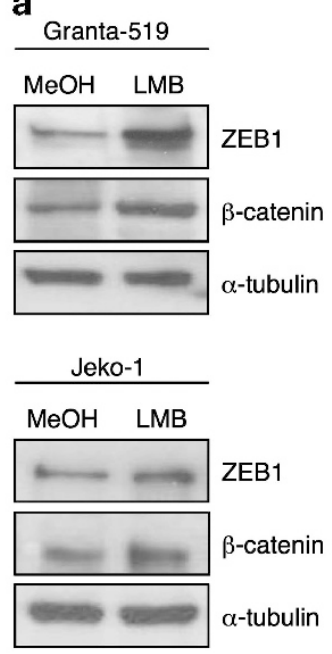

$\frac{\text { b Granta-519 }}{\text { Ctl Wnt3a }}$

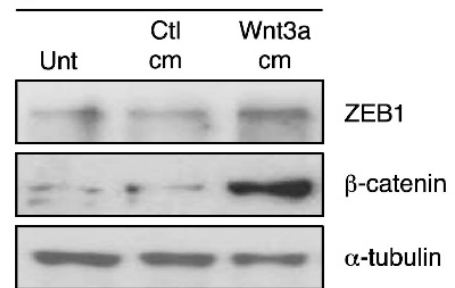

Jeko-1

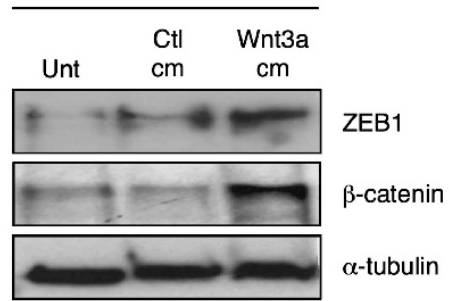

c

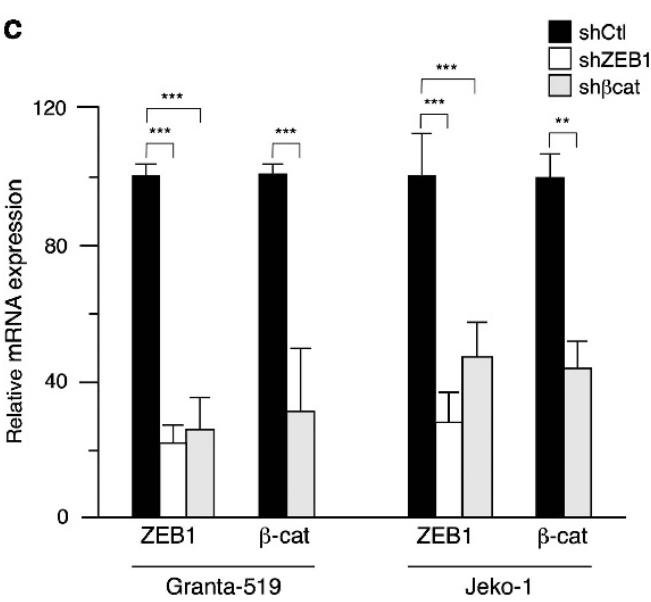

d

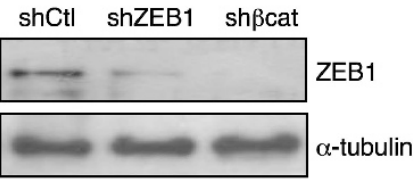

Figure 2 ZEB1 is induced by Wnt signaling in MCL cells. (a) Activation of Wnt signaling upregulates ZEB1. Granta-519 and Jeko-1 cells were incubated for $1 \mathrm{~h}$ with 10 $\mathrm{ng} / \mathrm{ml}$ of LMB or the same volume amount of LMB solvent (70\% methanol, MeOH). Cell lysates were assessed for ZEB1 (H-102), $\beta$-catenin (clone 14) and $\alpha$-tubulin (B5-1-2). (b) As in a, but cells were incubated for $24 \mathrm{~h}$ with $50 \%$ (v/v) L-cell control- and L-cell-Wnt3a-conditioned media (Ctl-cm and Wnt3a-cm, respectively). (c) ZEB1 mRNA expression in MCL cells depends on $\beta$-catenin. Granta-519 and Jeko-1 MCL cells knocked down with specific shRNAs for ZEB1 (shZEB1) or $\beta$-catenin (sh $\beta$ cat) or transfected with shRNA control (shCtl) were assessed for ZEB1 and $\beta$-catenin mRNA levels by qRT-PCR with respect to GAPDH. Statistical significance was assessed by a Mann-Whitney U-test: ${ }^{* *} P<0.01$ and ${ }^{* * *} P<0.001$. (d) As in $\mathbf{c}$, but assessed in Granta-519 cells by western blot for ZEB1 (H-102) along with $\alpha$-tubulin (B5-1-2) as the loading control

ZEB1 expression regulates genes involved in proliferation and apoptosis in MCL cells and promotes MCL tumor growth in vivo. Beyond the translocation of cyclin D1, cell cycle deregulation by secondary genetic alterations of components of the $\mathrm{p} 16^{\mathrm{INK} 4 \mathrm{a}} / \mathrm{CDK} 4 / \mathrm{Rb} 1$ or

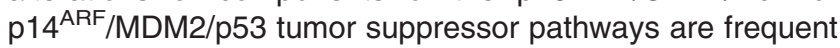
in MCLs. ${ }^{1,40,43,44}$ ZEB1 is known to be repressed by Rb1 and in turn to repress several cyclin-dependent kinase inhibitors (for example, p15 ${ }^{\mathrm{INK} 4 \mathrm{~b}}, \mathrm{p} 19^{\mathrm{ARF}}$, and p21 $\left.{ }^{\mathrm{CIP} / \mathrm{WAF} 1}\right){ }^{45-47}$

In several hematological malignancies, including MCLs, Wnt signaling enhances cell viability, whereas its inhibition reduces it. $5,15,17,18,20$ We therefore questioned whether ZEB1 determines enhanced cell viability in MCL cells. As shown in Figure $4 a$, knockdown of ZEB1 resulted in a partial decrease of MCL basal cell viability that was similar to that obtained by interference of $\beta$-catenin. Collectively, the results shown this far indicate that ZEB1 expression regulates MCL cell viability.
Next, we questioned whether ZEB1-mediated enhanced viability in MCLs involved greater cell proliferation. Knockdown of ZEB1 (and $\beta$-catenin) reduced the proliferation of MCL cells by over $40 \%$ respect to control cells as assessed by ${ }^{3} \mathrm{H}$-Thymidine and BrdU incorporation (Figures $4 \mathrm{~b}$ and $\mathrm{c}$ ). Consistent with this finding, we found that ZEB1 was expressed in proliferating $B$ cells at the germinal centers of tonsils but was almost absent in quiescent cells at the mantle zone (Supplementary Figures S3A and B). Likewise, ZEB1 was upregulated in normal $B$ cells following activation with mitogenic stimuli (Supplementary Figure S3C).

Highly proliferative MCLs tend to have a poorer clinical outcome. ${ }^{40,48,49}$ In addition to Ki-67, traditionally used in clinical applications, ${ }^{48}$ gene and protein expression analyses in primary MCLs have identified different markers associated to proliferation that independently or jointly serve as predictors of worse prognosis in MCL. ${ }^{40,48,49}$ We therefore explored 

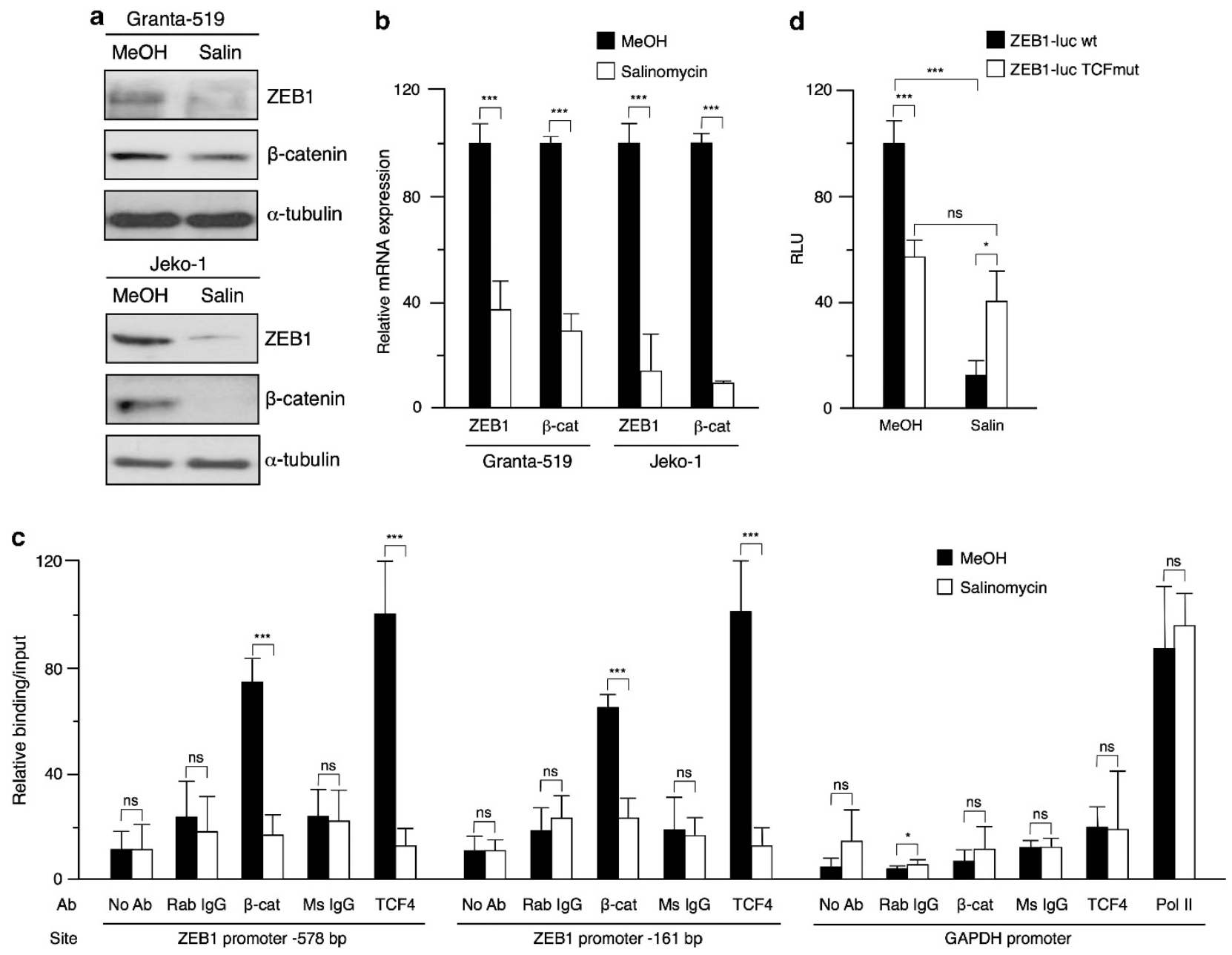

Figure 3 Salinomycin inhibits ZEB1 expression. (a) Granta-519 and Jeko-1 MCL cells infected with shCtl or shZEB1 were treated with $5 \mu \mathrm{m}$ of salinomycin for $48 \mathrm{~h}$ or an equal volume amount of its solvent (methanol, MeOH). Lysates were immunoblotted for ZEB1 (H-102) and $\beta$-catenin (clone 14) using $\alpha$-tubulin (B5-1-2) as the loading control. (b) Salinomycin inhibits ZEB1 mRNA expression. As in a, but assessing relative ZEB1 and $\beta$-catenin mRNA by qRT-PCR with respect to GAPDH. Statistical significance was assessed by a $t$-test: ${ }^{* * *} P<1 \times 10^{-5}$. (c) Salinomycin inhibits binding of $\beta$-catenin and TCF4 to TCF-LEF sites at -578 and -161 bp of the ZEB1 promoter. qRT-PCR amplification of fragments of the ZEB1 and GAPDH promoters immunoprecipitated in ChIP assays from Granta-519 cells treated for $48 \mathrm{~h}$ with either MeOH or $5 \mu \mathrm{M}$ salinomycin. The GAPDH promoter, lacking TCF-LEF sites, was included as negative control. qRT-PCR of the GAPDH promoter from a ChIP with an Ab against RNA Pol II was included as the positive control. Values represent relative binding versus input. Statistical significance was assessed by a Mann-Whitney $U$-test: ${ }^{*} P<0.05$; ${ }^{* * *} P<0.001$; NS, not significant, $P>0.05$. (d) Salinomycin inhibits TCF/LEF-mediated ZEB1 transcription. 293T cells exposed to $5 \mu$ m salinomycin were transfected with $0.5 \mu \mathrm{g}$ of a luciferase reporter for the human ZEB1 promoter either wild type or mutated for TCF/LEF-binding sites at -161 and $-578 \mathrm{bp}$. Relative luciferase units (RLU) were determined as described in Materials and Methods. Statistical significance was assessed by a $t$-test as follows: ${ }^{*} P<1 \times 10^{-3} ;{ }^{* \star \star} P<1 \times 10^{-5}$; NS, $P>1 \times 10^{-3}$

whether ZEB1 expression associates to proliferationassociated genes. Indeed, ZEB1 was positively correlated with the proliferation signature average defined by Rosenwald et al. ${ }^{40}$, a number of genes included in that signature (HMGB2, UHRF1, and CENPF), as well as well-known proliferationrelated genes like MYC and MKI67 (Supplementary Table S1). Such correlation was then validated in MCL cells by quantitative real-time PCR (qRT-PCR). As shown in Figure 4d, knockdown of ZEB1 in MCL cells resulted in the downregulation of HMGB2, UHRF1, CENPF, MYC and MKI67 mRNA. Interference of ZEB1 also caused a downregulation of CCND1/cyclin D1 mRNA and protein in MCL cells (Figure $4 d$ and Supplementary Figure S3D).

The above results indicate that ZEB1 promotes proliferation in MCL cells and suggest that ZEB1 could have a role in progression of MCLs. To test that hypothesis, MCL cells interfered with a shRNA control (shCtl) or a specific shRNA against ZEB1 (shZEB1) were inoculated in severe-combined immunodeficient (SCID) mice. As shown and discussed below (Figure 6b), knockdown of ZEB1 resulted in a dramatic reduction in tumor volume.

In addition to altered cell cycle and enhanced proliferation, MCL cells display deregulated apoptosis. ${ }^{1}$ Thus, anti-apoptotic genes such as MCL1, BCL2, and BICR5/Survivin have been found overexpressed in MCLs, frequently correlating with higher proliferation. ${ }^{1,10,11,50}$ To determine whether the reduced viability of ZEB1 knockdown MCL cells also involves increased apoptosis, we examined caspase 3 and 7 activities. As shown in Supplementary Figure S3E, and relative to DMSO that was used as control, knockdown of ZEB1 increased by around $20 \%$ 

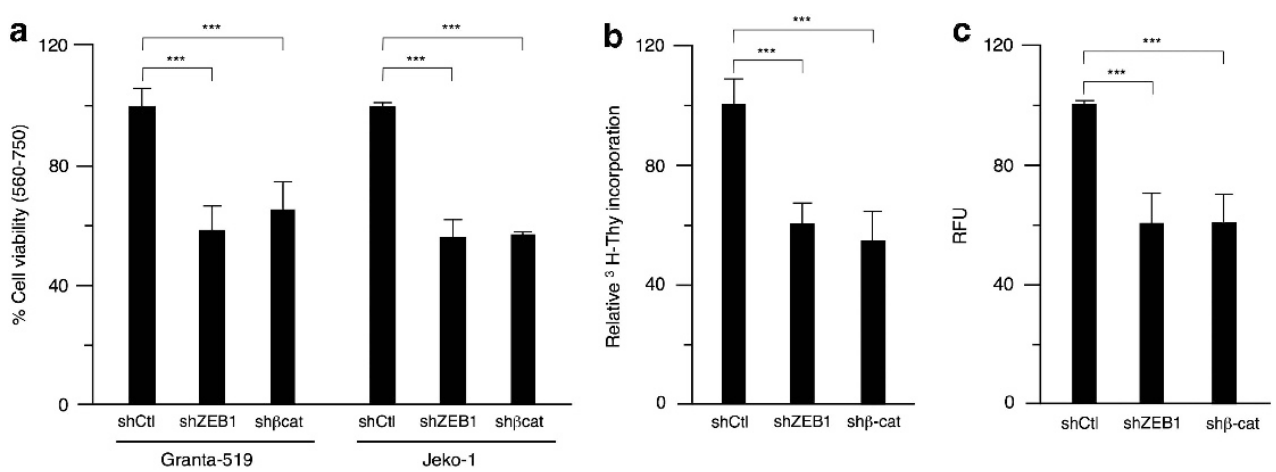

d
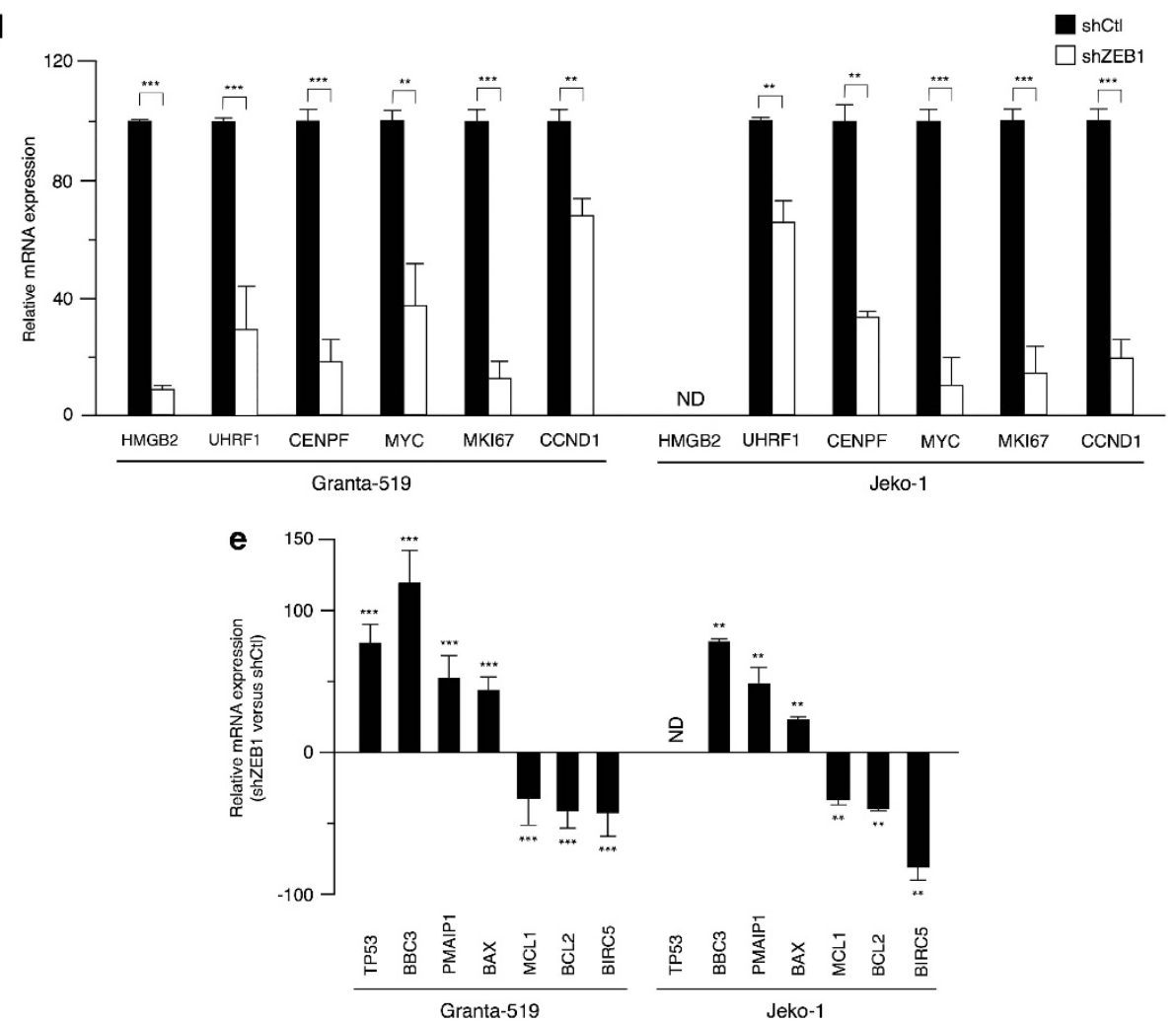

Figure 4 ZEB1 promotes increased viability and proliferation in MCL cells. (a) Granta-519 cells and Jeko-1 MCL cells knocked down for ZEB1, $\beta$-catenin, or infected with a control shRNA were assessed for cell viability by MTT assays. Values are represented relative to shCtl cells. Statistical significance was assessed by a Mann-Whitney $U$-test with ${ }^{* * *} P<0.001$. (b) Knockdown of ZEB1 reduces MCL cell proliferation. As in a, Granta-519 MCL cells knocked down for ZEB1 or $\beta$-catenin or infected with a control shRNA were assessed for ${ }^{3} \mathrm{H}$-Thymidine incorporation. Statistical significance was assessed by a $t$-test with the following key: ${ }^{* \star} P<1 \times 10^{-5}$. (c) As in $\mathbf{b}$, but cell proliferation was assessed by BrdU incorporation. Statistical significance was assessed by a Mann-Whitney U-test with ${ }^{* \star \star} P<0.001$. (d) ZEB1 positively regulates proliferation-associated genes. ZEB1 knockdown downregulates the expression of proliferation-associated genes HMGB2, UHRF1, CENPF, MYC, MKI67/Ki-67 and CCND1/Cyclin D1. MCL cells were interfered with either shCtl or shZEB1 and mRNA levels of were assessed by qRT-PCR. ND, non-detectable expression of HMGB2 in Jeko-1 cells. Statistical significance was assessed by a $t$-test with the following key: ${ }^{* \star \star} P<1 \times 10^{-5},{ }^{* \star} P<1 \times 10^{-4}$. (e) Knockdown of ZEB1 in MCL cells upregulates pro-apoptotic genes (TP53, BBC3/Puma, PMAIP1/Noxa, and BAX) and downregulates anti-apoptotic ones (MCL1, BCL2, and BIRC5/Survivin). MCL cells interfered with shCtl or shZEB1 were assessed for relative mRNA expression of the indicated genes by qRT-PCR. Relative mRNA levels in shZEB1 cells are expressed relative to shCtl cells. ND, not detectable expression of p53 in Jeko-1 cells. Statistical significance of the expression of each gene in MCL cells knocked down for ZEB1 (shZEB1) versus those interfered with shCtl was assessed by a Mann-Whitney U-test with the following key: ${ }^{* *} P<0.01,{ }^{* *} P<0.001$

the activity of these caspases. Accordingly, and compared with control cells, interference of ZEB1 in MCL cells reduced the expression of anti-apoptotic genes MCL1, BCL2 and BIRC5 and increased levels of pro-apoptotic TP53, BBC3/Puma, PMAIP1/ Noxa and BAX (Figure 4e; Supplementary Figure S3D). Data shown this far indicate that ZEB1 promotes proliferation and activates anti-apoptosis and proliferation-associated genes.
ZEB1 determines differential response to chemotherapy drugs. MCL is characterized by a poor response to chemotherapy. ${ }^{22,23}$ Current first-line strategies in $\mathrm{MCL}$ comprise combinations of anti-CD20 antibody with doxorubicin, vincristine, cyclophosphamide and prednisone or with a hyperfractionated treatment of the above alternated with methotrexate and cytarabine. ${ }^{1,22,23}$ Gemcitabine is also 
used in second-line treatment of relapsed and refractory MCLs. 22

An important mechanism in the resistance of tumors to chemotherapy is the deregulated expression of proteins involved in the transport of anticancer drugs into/from malignant cells. ${ }^{51}$ Thus, expression of a number of efflux transporters such as MDR1 (also referred as ABCB1/P. glycoprotein), MRP1 (ABCC1), MRP2 (ABCC2), MRP5 (ABCC5) and MXR (ABCG2) determines increased resistance to doxorubicin. In the meantime, resistance to cytarabine and gemcitabine could result from a decrease in their cellular uptake by the influx transporters ENT1 (SLC29A1) and CNT1 (SLC28A1). MDR1 has been found overexpressed in primary MCL, while ENT1 expression correlates with the sensitivity of MCL cells to gemcitabine. ${ }^{52,53}$
We therefore explored whether ZEB1 could regulate any of these drug transporters in two MCL cell lines. MDR1, MRP1, MRP5 and ENT1 mRNAs were expressed at higher levels compared with MRP2, MXR and CNT1 in MCL cells. Interference of ZEB1 resulted in the differential regulation of these genes, displaying some degree of cell line-dependent variability (Figures $5 a$ and $b$ ).

Regulation by ZEB1 of some of these efflux and influx drug transporters was also examined in the TMA of MCLs used in Figure 1a. In line with the results in cell lines of Figures $5 a$ and $b$, we found that ZEB1 was positively correlated with MRP1 and MXR and inversely correlated with CNT1 (Figure $5 \mathrm{c}$ and Table 2).

In light of the regulation of drug transporters by ZEB1, we next investigated whether ZEB1 expression could modulate the dose response of MCL cells to chemotherapy
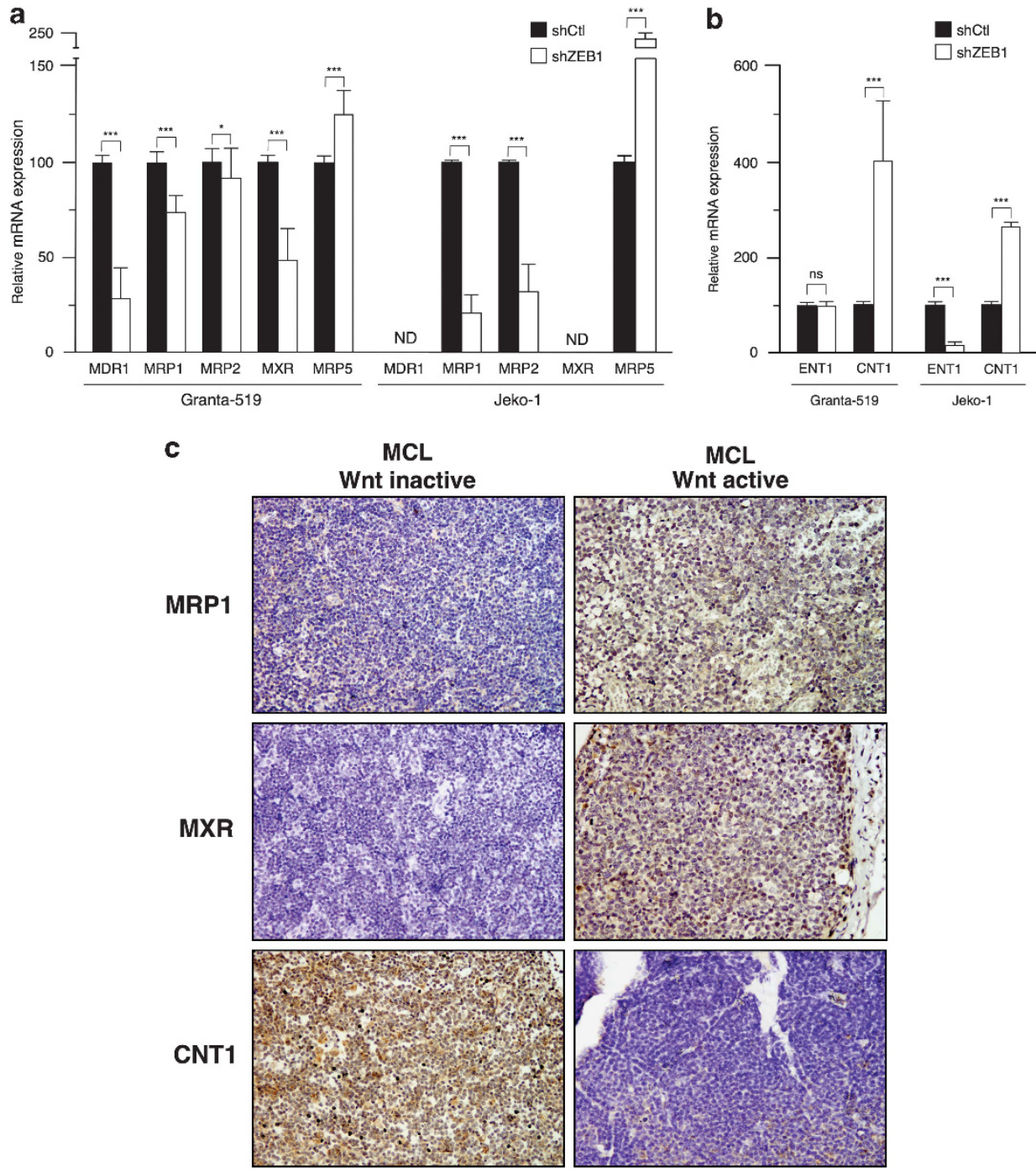

Figure 5 ZEB1 regulates the expression of drug transporters in MCL cells. (a) ZEB1 regulates the expression of efflux drug transporters in MCL cells. MCL cells interfered with shCtl or shZEB1 were assessed for relative mRNAs of efflux transporters MDR1, MRP1, MRP2, MXR and MRP5 by qRT-PCR. Statistical significance in a and $\mathbf{b}$ was assessed by a Mann-Whitney U-test with the following key: ${ }^{*} P<0.05$; ${ }^{* \star \star} P<0.001$; NS, not significant, $P>0.05$. ND, not detectable levels. (b) As in a, but for influx drug transporters ENT1 and CNT1. (c) As in Figure 1a, representative cases of MCL active or inactive for Wnt, as defined by the expression of $\beta$-catenin, were immunostained for MRP1 (QCRL-1), MXR (B-25), and CNT1 (H-70). Magnification of $\times 200$. Statistical significance of the correlation between ZEB1 and these drug transporters is shown in Table 2 
drugs. We found that knockdown of ZEB1 increased the sensitivity of $\mathrm{MCL}$ cells to doxorubicin, cytarabine and gemcitabine (Figure $6 a$ in Granta-519 cells and data not shown for Jeko-1 cells). Interference of ZEB1 expression did not alter the response of MCL cells to vincristine (Figure 6a).

The increased resistance to doxorubicin imposed by ZEB1 was then tested in vivo using a mouse xenograft model of MCL. SCID mice inoculated with Granta-519 MCL cells interfered for either shZEB1 or shCtl were later treated with either doxorubicin or vehicle alone. The response of the

Table 2 Correlation between ZEB1 and drug transporters in MCL

\begin{tabular}{lclc}
\hline & & & ZEB1 \\
\hline Spearman's $\rho$ & MRP1 & Correlation coefficient & $\rho=0.790$ \\
& & Significance (two-tailed) & $P<0.001$ \\
& & $n$ & 32 \\
& MXR & Correlation coefficient & $\rho=0.672$ \\
& & Significance (two-tailed) & $P<0.001$ \\
& CNT1 & Correlation coefficient & $\rho=-0.423$ \\
& & Significance (two-tailed) & $P=0.016$ \\
& & & 32
\end{tabular}

xenografted MCL tumors to doxorubicin was followed over time. Tumor growth was decreased by treatment of mice with doxorubicin and was further reduced by ZEB1 knockdown (Figure 6b). Salinomycin also reduced the growth of MCL tumors in this mouse xenograft model (Supplementary Figure S4B). Altogether, these results indicate that ZEB1 determines a differential response to chemotherapy drugs and that its knockdown enhances the cytotoxic effect of doxorubicin, cytarabine and gemcitabine in established MCL cells and tumor growth reduction by doxorubicin in a $\mathrm{MCL}$ xenograft model in mice.

Salinomycin enhances sensitivity to MCL chemotherapy drugs and synergizes with doxorubicin. In light of our findings that salinomycin inhibited ZEB1 expression and that ZEB1 expression determined increased resistance to doxorubicin, cytarabine and gemcitabine, we questioned whether salinomycin could sensitize MCL cells to these three drugs. To test this hypothesis, we examined the effect of combining suboptimal doses (reducing MCL cell viability to $80 \%$ as determined in Figure $6 \mathrm{a}$ and Supplementary Figure S4a) of salinomycin and either doxorubicin, cytarabine or gemcitabine. a

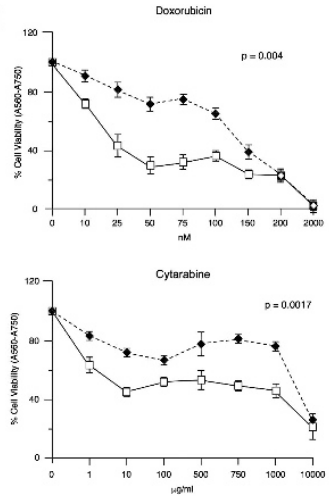

b

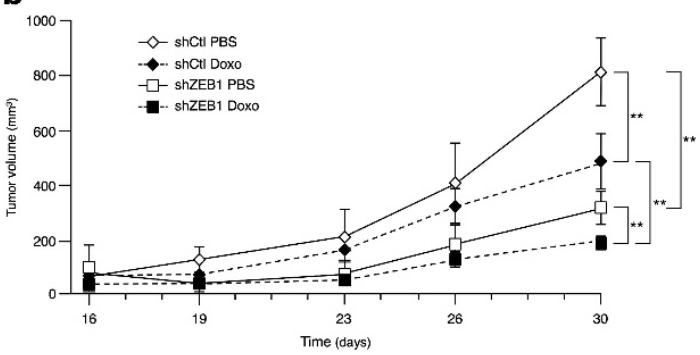

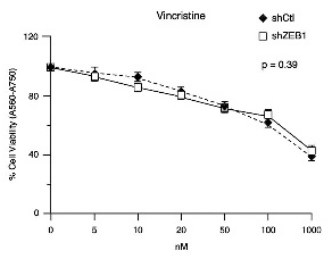

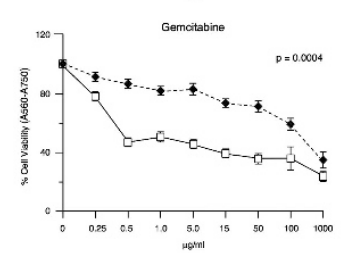

e

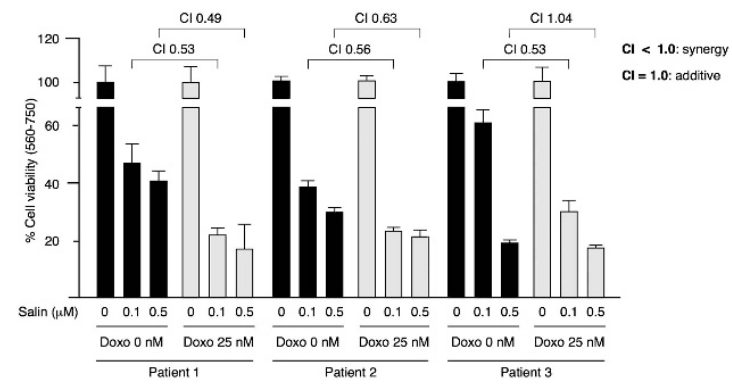

c

d
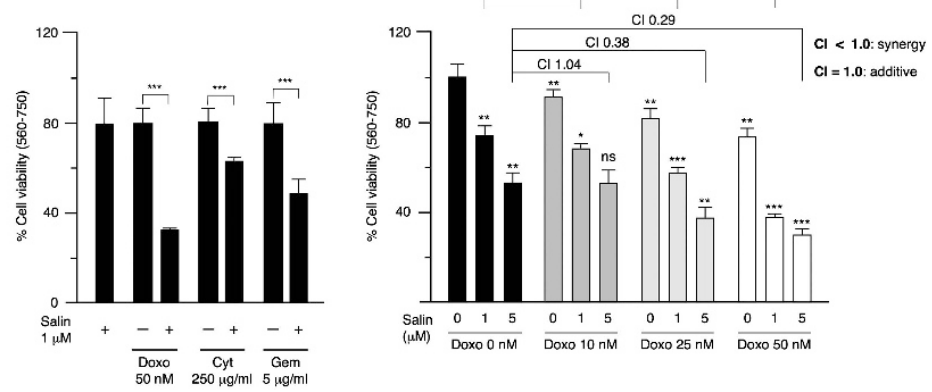

Figure 6 ZEB1 determines differential response to chemotherapy drugs in MCL, which is modulated by salinomycin. (a) Granta-519 MCL cells interfered with shCtl or shZEB1 were assessed by MTT for their dose response to doxorubicin, vincristine, cytarabine or gemcitabine. Values in the presence of drugs were normalized to the untreated condition. Statistical significance in panels $\mathbf{a}, \mathbf{b}$ and $\mathbf{c}$ was assessed by a paired $t$-test. (b) Doxorubicin decreases tumor growth, which further declines after ZEB1 knockdown. Granta-519 shCtl or Granta-519 shZEB1 cells were injected subcutaneously in CB17-SCID mice. Mice were then treated twice a week with $1.25 \mathrm{mg} / \mathrm{kg}$ of doxorubicin or the vehicle solvent (PBS) and tumor volume measured at the indicated time points. Statistical significance was assessed by a Mann-Whitney U-test with ${ }^{\star *} P<0.01$. (c) Salinomycin increases sensitivity to chemotherapy drugs in MCL cells. Granta- $519 \mathrm{MCL}$ cells were treated during $48 \mathrm{~h}$ with suboptimal doses (killing $80 \%$ of cells by MTT, see Figure $6 \mathrm{a}$ and Supplementary Figure S4a) of salinomycin (1 $\mu \mathrm{m})$ and either doxorubicin $(50 \mathrm{~nm})$, cytarabine $(250 \mu \mathrm{g} / \mathrm{ml})$ or gemcitabine $(5 \mu \mathrm{g} / \mathrm{ml})$. (d) Salinomycin synergizes with doxorubicin in their cytotoxic effect in an established MCL cell line. Granta-519 MCL cells were exposed during $48 \mathrm{~h}$ to different combinations of salinomycin and doxorubicin. In panels $\mathbf{d}$ and $\mathbf{e}$, the existence of a synergistic effect between both drugs was assessed by the Chou-Talalay Cl method ${ }^{54}$ as described in Supplementary Materials and Materials and Methods. Cl values below 1.0 indicate synergism. Statistical significance between each dose of salinomycin plus doxorubicin ( $10 \mathrm{~nm}, 25 \mathrm{~nm}$ or $50 \mathrm{~nm}$ ) with respect to same dose without doxorubicin was assessed by a Mann-Whitney U-test with the following key: ${ }^{*} P<0.05$; ${ }^{* *} P<0.01$; ${ }^{* \star *} P<0.001$; NS, not significant, $P>0.05$. (e) As in d, but using primary MCL cells from three patients. Note that doses in primary MCL cells were modified from those used in established cell lines 
Interestingly, as shown in Figure 6c, salinomycin increased the cytotoxic effect of these three drugs in MCL cells.

As the sensitizing effect of salinomycin was larger for doxorubicin, we explored whether there is a synergistic effect between both drugs in MCL cells as determined by a ChouTalalay combination index $(\mathrm{Cl})$ analysis. ${ }^{54,55}$ Using a range of doses for salinomycin and doxorubicin, we found that their combination displayed a pharmacological synergistic effect (Cl values below 1) on both Granta-519 MCL cells (Figure 6d) and primary cells from MCL patients (Figure 6e). These results indicate that the combination of salinomycin with conventional MCL chemotherapy drugs potentiate the effect of the latter.

\section{Discussion}

MCL ranks as one of the most aggressive lymphomas. Clinical, pathological and ontogenic evidence suggest the existence of significant heterogeneity within MCLs. ${ }^{1}$ In this regard, several classical transduction pathways involved in cancer (for example, NF- $\kappa \mathrm{B}$, Notch, PI3K/AKT/mTOR, and Wnt) are constitutively active in different subsets of MCLs. ${ }^{1,3-6}$ Here, we show that ZEB1, a transcription factor that has a key role in EMT and carcinoma progression, is found in the same subset of primary MCLs that express $\beta$ catenin. ZEB1 expression in MCL cells is dependent on Wnt as further activation of Wnt signaling upregulates ZEB1, whereas interference of the pathway - either by knockdown of $\beta$-catenin or treatment with Wnt inhibitor salinomycin - downregulates it. ZEB1 knockdown in MCL cells decreases cell viability and proliferation, downregulates anti-apoptotic and proliferation-associated genes and upregulates pro-apoptotic ones. Accordingly, knockdown of ZEB1 determined reduced $M C L$ tumor growth in xenografted mice. ZEB1 regulates the expression of proteins involved in the transport into/out of $\mathrm{MCL}$ cells of chemotherapy drugs, and we showed that ZEB1 expression in MCL cells determines resistance to doxorubicin, cytarabine and gemcitabine but not to vincristine. Lastly, we found that downregulation of ZEB1 by salinomycin increases sensitivity of MCL cells to the cytotoxic effect of these three drugs, and that salinomycin and doxorubicin display a synergistic effect in established and primary MCL cells.

Aberrant activation of Wnt is considered a key step in the pathogenesis and progression of many solid tumors, ${ }^{26}$ but mounting evidence indicates that Wnt also has important roles in hematological malignancies, including MCL. ${ }^{20}$ ZEB1 is expressed in cancer cells at the invasive front of carcinomas where it triggers a mesenchymal and pro-invasive phenotype. ${ }^{36,37,39}$ We showed here that ZEB1 expression in MCL cells is dependent on Wnt signaling. It is noteworthy that other signaling pathways constitutively active in subsets of MCLs (for example, NF $\kappa \mathrm{B}$, Notch, PI3K/AKT, and TGF- $\beta)^{1}$ are also upstream inducers of ZEB1. ${ }^{37}$ In addition, there is also significant cross talk among many of these pathways. PI3K/ AKT is constitutively active, whereas GSK-3 $\beta$ is inactivated in subsets of MCLs. ${ }^{5,9}$ Inhibition of AKT downregulates cyclin D1 in MCL cells by promoting GSK-3 $\beta$-dependent degradation. ${ }^{9}$ GSK-3 $\beta$ has opposing functions over Wnt as it activates signaling at the receptor level but promotes degradation of $\beta$-catenin. ${ }^{26}$ In sum, it cannot be excluded that expression of ZEB1 in MCL cells is modulated by additional signals beyond Wnt.

Sustained proliferative signaling and resistance to apoptosis are classical cancer cell hallmarks crucially involved in the pathogenesis of malignant neoplasias. In addition to the translocation and overexpression of cyclin D1, a number of other genetic and nongenetic alterations resulting in deregulated cell cycle progression and/or reduced apoptosis have been reported in MCLs. ${ }^{1,10,11,40,43,44,48,49}$ In that line, pharmacological inhibitors of Wnt signaling or knockdown of components of the pathway reduce proliferation and trigger apoptosis in MCL cells. ${ }^{5,6}$

Our data show that ZEB1 could have a role in the regulation of proliferation and apoptosis in MCL. On the one hand, ZEB1 correlated with well-established proliferation-associated genes in primary MCL (HMGB2, UHRF1, CENPF, MYC, $M K I 67$, and CCND1), and ZEB1 knockdown downregulated expression of these genes. Consistent with these observations, ZEB1 interference reduces cell proliferation in MCL cells and $\mathrm{MCL}$ tumor growth in xenograft models. Likewise, ZEB1 is expressed in proliferating B cells at the germinal center and is upregulated upon mitogenic stimulation of peripheral blood B cells. In this line, it is worth noting that mesenchymal and neural progenitors display decreased proliferation in mice deficient for $Z E B 1,{ }^{47}$ and that, in fibroblasts and epithelial cells, ZEB1 is repressed by the p16/Rb1 tumor suppressor pathway, while, in turn, ZEB1 represses $\mathrm{p} 15^{\text {INK4b }}, \mathrm{p} 19^{\mathrm{ARF}}$ and $\mathrm{p} 21^{\mathrm{CIP} / \mathrm{WAF} 1}{ }^{45-47}$

At the same time, our results here show that ZEB1 expression in MCL cells determines resistance to apoptosis. ZEB1 knockdown increased caspase 3/7 activity along with the downregulation of anti-apoptotic MCL1, BCL2 and BIRC5 and the upregulation of the pro-apoptotic genes TP53, BBC3, $P M A I P 1$ and $B A X$. The Bcl2 pathway is often deregulated in MCLs and several of its members (for example, Bcl2 and Mcl1) are frequently overexpressed. ${ }^{1,10,56}$ BIRC5/Survivin is also frequently overexpressed in MCLs with higher proliferation. ${ }^{50}$ By promoting enhanced viability and proliferation and reduced apoptosis in MCL cells, ZEB1 could potentially have a role in the pathogenesis of MCLs.

Although originally selected for its cytotoxicity in undifferentiated epithelial cells, salinomycin has been recently shown to induce apoptosis in leukemic cells through inhibition of Wnt signaling. ${ }^{16}$ Our data indicate that salinomycin also kills MCL cells, inhibits Wnt signaling and represses ZEB1 at the transcriptional level through a TCF-LEF-dependent mechanism. It is noteworthy that salinomycin inhibits the efflux drug transporter MDR $1^{57}$ that we reported here to be under positive regulation by ZEB1. Exposure of $\mathrm{MCL}$ cells to salinomycin increased their sensitivity to several MCL chemotherapy drugs. Interestingly, at some dose combinations, salinomycin and doxorubicin display a synergistic cytotoxic effect in established and primary MCL cells. These results highlight the potential use of selective Wnt inhibitors in MCL treatment. By downregulating ZEB1, Wnt inhibitors would increase sensitivity of $\mathrm{MCL}$ cells to conventional chemotherapy regimes. Recent progress in the discovery of specific Wnt inhibitors that reduce the tumorigenicity and growth of solid tumors also opens new avenues for interfering Wnt signaling in hematological malignancies. ${ }^{58,59}$ 
In sum, this study has identified ZEB1 as a new biomarker in MCLs, where it promotes cell proliferation, resistance to apoptosis and enhanced tumor growth, possibly participating in the progression of MCLs. At the same time, ZEB1 expression defines a differential response to chemotherapy drugs, thus also setting ZEB1 as a potential predictive biomarker and therapeutic target in this lymphoma.

\section{Materials and Methods}

Antibodies, plasmids, oligonucleotides and shRNAs. Description and source of antibodies, plasmids, oligonucleotides and shRNA lentivirus used in the study are detailed in Supplementary Information.

Human samples. A series of $46 \mathrm{MCL}$ cases was obtained from the Tissue Bank of the National Cancer Center (CNIO, Madrid, Spain). All diagnostic samples were histologically classified as MCL according to the World Health Organization criteria and representative areas were used to construct a TMA. Tonsillar and peripheral blood B cells were obtained from samples donated by the Tissue Bank at Hospital Sant Joan de Deu (Barcelona, Spain) and the Catalan Blood and Tissue Bank (Barcelona, Spain), respectively, and their purification is detailed in Supplementary Information. Primary MCL cells originated from three untreated MCL patients diagnosed according to the World Health Organization criteria and isolated from peripheral blood as detailed in Supplementary Information. Procurement and use of human samples had the informed consent of patients and donors and conformed with the principles set out in the World Medical Association's Declaration of Helsinki and had the approval of the respective local ethics research committees.

Gene microarray data sets for survival data. Two published data sets of MCLs were used to calculate overall survival associated to ZEB1. In the data set GEO ID GSE10793, corresponding to Blenk et al.., ${ }^{41}$ survival for up to 8 years was available for 66 untreated cyclin D1-positive MCL patients, 63 of whom also have ZEB1 expression data. Gene chip measurements were performed using NCI/ Staudt human $15 \mathrm{~K}$ v13 arrays. The probe 33032_1 was used for ZEB1. The data set corresponding to Rosenwald et al. ${ }^{40}$ has been published at http:/l www.IImpp.nih.gov/ MCL/ and contains 92 untreated MCL patients, 64 of whom were cyclin D1 positive. Gene chip measurements in these cyclin D1-positive cases were performed using lymphochip DNA microarrays. ${ }^{60}$ Probe 16935 was used for ZEB1.

Cells and cell culture. Granta-519, Jeko-1, 293T and primary MCL cells were cultured in DMEM or RPMI (Lonza, Verviers, Belgium) supplemented with $10 \%$ FCS (Sigma-Aldrich, St Louis, MO, USA). L-cells stably expressing Wnt3a cDNA (LWnt3a cells) or its corresponding empty vector (L-CtI cells) were cultured in DMEM plus $10 \%$ FCS under selection with $0.4 \mathrm{mg} / \mathrm{ml}$ of G418 (Fisher Scientific, Fair Lawn, $\mathrm{NJ}$, USA). Where indicated, cells were treated with $100 \mathrm{~nm}$ of PMA (Sigma-Aldrich) for $72 \mathrm{~h}, 10 \mathrm{ng} / \mathrm{ml}$ LMB (Sigma-Aldrich, in $70 \%$ methanol) for $1 \mathrm{~h}$, with $50 \%$ (v/v) of either L-Ctl- or L-Wnt3a cells-conditioned media for 24-48 h. For chemotherapy drug response experiments, MCL cells were treated with different drugs in time course experiments as described in Supplementary Information. Cell transfections were performed as described in Supplementary Information.

Determination of protein and RNA expression and transcriptional assays. Analysis of protein expression by immunohistochemistry or westem blot is described in Supplementary Information. qRT-PCR, transcriptional assays and ChIP assays were performed as described in the Supplementary Information.

Cell viability and proliferation assays. Cell viability in basal conditions and in response to drugs was determined by conventional MTT assays as detailed in Supplementary Information. Assessment of caspase 3/7 activity was determined using the Caspase-Glo 3/7 kit (Promega, Madison, WI, USA) as per manufacturer's instructions and further detailed in Supplementary Data. Cell proliferation was assessed by incorporation of either ${ }^{3} \mathrm{H}$-Thymidine or BrdU as described in Supplementary Information.

Mouse xenograft model. A total of $1 \times 10^{7}$ Granta-519 shCtl or Granta-519 shZEB1 cells resuspended in $100 \mu \mathrm{l}$ of PBS and $100 \mu \mathrm{l}$ Matrigel basement membrane matrix (Becton Dickinson Biosciences, Bedford, MA, USA) were inoculated subcutaneously into the right lower dorsum of 7-week-old CB17-SCID female mice (Janvier) according to a protocol approved by the Animal Experimentation Committee of the University of Barcelona. Sixteen days after the injection of MCL cells, mice were randomly assigned into several cohorts of five each and were administered intraperitoneally with either $1.25 \mathrm{mg} / \mathrm{kg}$ twice a week of doxorubicin (Pfizer Inc, New York, NY, USA), $2.0 \mathrm{mg} / \mathrm{kg}$ of salinomycin monosodium salt hydrate Vetranal daily (Sigma-Aldrich) or the equal volume amount of vehicle (PBS). Tumor growth was followed up as by measuring the shortest and longest diameter of tumors with calipers at 2- to 5-day intervals. Tumor volumes in $\mathrm{mm}^{3}$ were calculated according to the following formula: (the shortest diameter $)^{2} \times($ the longest diameter $) \times 0.5$. Drug treatment lasted for 30 days and mice were euthanized $24 \mathrm{~h}$ after the last drug administration.

Statistical analysis. Statistical analysis of the data was conducted independently by two experts (GCB/RE and $B G$ ) with identical results. Determination of normal distribution of data and statistical test used is detailed in Supplementary Materials and Materials and Methods. Synergistic effect between chemotherapy drugs was determined by the $\mathrm{Cl}$ method ${ }^{54}$ as indicated in Supplementary Information.

\section{Conflict of Interest}

The authors declare no conflict of interest.

Acknowledgements. We are indebted to Dr. Elias Campo for helpful insights and critical reading of the manuscript. We also thank M Sanchez-Beato, ME Castillo, the Tumour Bank at CNIO (MJ Artiga, M Morente) and physicians for completing and retrieving clinical data and samples. We are grateful to all researchers who provided us with reagents (see Materials and Methods) and apologize to those whose work was cited indirectly through reviews because of space limitations. This work was developed at the Centre de Recerca Biomèdica Cellex, Barcelona. The different parts of this study were independently funded by grants from the Ministry of Economy and Competitiveness (BFU2010-15163), Avon Cosmetics S.A.U. (ACSAU), Spanish Association Against Cancer, Academy of Medical and Health Sciences of Catalonia and the Balearic Islands, La Caixa Foundation (LCF) and the European Commission to AP. EST's salary was partly funded by ACSAU, LCF and CIBERehd. LF was recipient of a PhD scholarship from the Catalan Agency for Universities and Research (AGAUR). LF and LS are funded by PhD scholarships from the Spanish Ministry of Education, Culture and Sports (FPU/AP2012-1222 and FPU/AP2010-4495, respectively).

1. Jares $\mathrm{P}$, Colomer $\mathrm{D}, \mathrm{Campo} \mathrm{E}$. Molecular pathogenesis of mantle cell lymphoma. J Clin Invest 2012; 122: 3416-3423.

2. Gesk S, Klapper W, Martín-Subero Jl, Nagel I, Harder L, Fu K et al. A chromosomal translocation in cyclin D1-negative/cyclin D2-positive mantle cell lymphoma fuses the CCND2 gene to the IGK locus. Blood 2006; 108: 1109-1110.

3. Rizzatti EG, Falcão RP, Panepucci RA, Proto-Siqueira R, Anselmo-Lima WT, Okamoto OK et al. Gene expression profiling of mantle cell lymphoma cells reveals aberrant expression of genes from the PI3K-AKT, WNT and TGF $\beta$ signalling pathways. Br J Haematol 2005; 130: 516-526.

4. Roué G, Pérez-Galán P, López-Guerra M, Villamor N, Campo E, Colomer D. Selective inhibition of IkappaB kinase sensitizes mantle cell lymphoma $B$ cells to TRAIL by decreasing cellular FLIP level. J Immunol 2007; 178: 1923-1930.

5. Gelebart P, Anand M, Armanious H, Peters AC, Dien Bard J, Amin HM et al. Constitutive activation of the Wnt canonical pathway in mantle cell lymphoma. Blood 2008; 112 : $5171-5179$.

6. Ortega-Paino E, Fransson J, Ek S, Borrebaeck CA. Functionally associated targets in mantle cell lymphoma as defined by DNA microarrays and RNA interference. Blood 2008; 111: $1617-1624$.

7. Leshchenko VV, Kuo PY, Shaknovich R, Yang DT, Gellen T, Petrich A et al. Genomewide DNA methylation analysis reveals novel targets for drug development in mantle cell lymphoma. Blood 2010; 116: 1025-1034.

8. Kimura Y, Arakawa F, Kiyasu J, Miyoshi H, Yoshida M, Ichikawa A et al. The Wnt signaling pathway and mitotic regulators in the initiation and evolution of mantle cell lymphoma: gene expression analysis. Int J Oncol 2013; 43: 457-468.

9. Dal Col J, Zancai P, Terrin L, Guidoboni M, Ponzoni M, Pavan A et al. Distinct functional significance of Akt and mTOR constitutive activation in mantle cell lymphoma. Blood 2008; 111: 5142-5151. 
10. Hofmann WK, de Vos S, Tsukasaki K, Wachsman W, Pinkus GS, Said JW et al. Altered apoptosis pathways in mantle cell lymphoma detected by oligonucleotide microarray. Blood 2001; 98: 787-794.

11. Martinez N, Camacho Fl, Algara P, Rodriguez A, Dopazo A, Ruiz-Ballesteros E et al. The molecular signature of mantle cell lymphoma reveals multiple signals favoring cell survival. Cancer Res 2003; 63: 8226-8232.

12. Reya T, Duncan AW, Ailles L, Domen J, Scherer DC, Willert $K$ et al. A role for Wnt signalling in self-renewal of haematopoietic stem cells. Nature 2003; 423: 409-414.

13. Jamieson $\mathrm{CH}$, Ailles LE, Dylla SJ, Muiitjens M, Jones C, Zehnder JL et al. Granulocytemacrophage progenitors as candidate leukemic stem cells in blast-crisis CML. $N$ Engl J Med 2004; 351: 657-667.

14. Wang Y, Krivtsov AV, Sinha AU, North TE, Goessling W, Feng Z et al. The Wnt/ $\beta$-catenin pathway is required for the development of leukemia stem cells in AML. Science 2010; 327: $1650-1653$.

15. Lu D, Zhao Y, Tawatao R, Cottam HB, Sen M, Leoni LM et al. Activation of the Wnt signaling pathway in chronic lymphocytic leukemia. Proc Natl Acad Sci USA 2004; 101 3118-3123.

16. Lu D, Choi MY, Yu J, Castro JE, Kipps TJ, Carson DA. Salinomycin inhibits Wnt signaling and selectively induces apoptosis in chronic lymphocytic leukemia cells. Proc Natl Acad Sci USA 2011; 108: 13253-13257.

17. Yasui $H$, Hideshima $T$, Ikeda H, Ocio EM, Kiziltepe T, Vallet $S$ et al. Novel etodolac analog SDX-308 (CEP-18082) induces cytotoxicity in multiple myeloma cells associated with inhibition of $\beta$-catenin/TCF pathway. Leukemia 2007; 21: 535-540.

18. Khan NI, Bradstock KF, Bendall LJ. Activation of Wnt/ $\beta$-catenin pathway mediates growth and survival in B-cell progenitor acute lymphoblastic leukaemia. Br J Haematol 2007; 138: 338-348.

19. Derksen PW, Tjin E, Meijer HP, Klok MD, MacGillavry HD, van Oers MH et al. Illegitimate WNT signaling promotes proliferation of multiple myeloma cells. Proc Natl Acad Sci USA 2004; 101: 6122-6127.

20. Lento W, Congdon K, Voermans C, Kritzik M, Reya T. Wnt signaling in normal and malignant hematopoiesis. Cold Spring Harb Perspect Biol 2013; 5: a008011.

21. Valencia A, Román-Gómez J, Cervera J, Such E, Barragán E, Bolufer $P$ et al. Wnt signaling pathway is epigenetically regulated by methylation of Wnt antagonists in acute myeloid leukemia. Leukemia 2009; 23: 1658-1666.

22. Ghielmini M, Zucca E. How I treat mantle cell lymphoma. Blood 2009; 114: 1469-1476.

23. Dreyling M, Thieblemont C, Gallamini A, Arcaini L, Campo E, Hermine 0 et al. ESMO Consensus conferences: guidelines on malignant lymphoma. Part 2: marginal zone lymphoma, mantle cell lymphoma, peripheral T-cell lymphoma. Ann Oncol 2013; 24 857-877.

24. Jung HJ, Chen Z, McCarty N. Stem-like tumor cells confer drug resistant properties to mantle cell lymphoma. Leuk Lymphoma 2011; 52: 1066-1079.

25. Gupta PB, Onder TT, Jiang G, Tao K, Kuperwasser C, Weinberg RA et al. Identification of selective inhibitors of cancer stem cells by high-throughput screening. Cell 2009; 138 : 645-659.

26. Clevers H, Nusse R. Wnt/ $\beta$-Catenin Signaling and Disease. Cell 2012; 149: 1192-1205.

27. Spaderna S, Schmalhofer O, Hlubek F, Berx G, Eger A, Merkel S et al. A transient, EMT-linked loss of basement membranes indicates metastasis and poor survival in colorectal cancer. Gastroenterology 2006; 131: 830-840.

28. Wellner U, Schubert J, Burk UC, Schmalhofer O, Zhu F, Sonntag A et al. The EMT-activator ZEB1 promotes tumorigenicity by repressing stemness-inhibiting microRNAs. Nat Cell Biol 2009; 11: 1487-1495.

29. Sanchez-Tillo E, Lazaro A, Torrent R, Cuatrecasas M, Vaquero EC, Castells A et al. ZEB1 represses E-cadherin and induces an EMT by recruiting the SWI/SNF chromatinremodeling protein BRG1. Oncogene 2010; 29: 3490-3500.

30. Sanchez-Tillo E, de Barrios O, Siles L, Cuatrecasas M, Castells A, Postigo A. $\beta$-catenin TCF4 complex induces the epithelial-to-mesenchymal transition (EMT)-activator ZEB1 to regulate tumor invasiveness. Proc Natl Acad Sci USA 2011; 108: 19204-19209.

31. Sanchez-Tillo E, de Barrios O, Siles L, Amendola PG, Darling DS, Cuatrecasas M et a. ZEB1 Promotes invasiveness of colorectal carcinoma cells through the opposing regulation of UPA and PAI-1. Clin Cancer Res 2013; 19: 1071-1082.

32. Postigo A, Dean DC. ZEB represses transcription through interaction with the corepressor CtBP. Proc Natl Acad Sci USA 1999; 96: 6683-6688.

33. Postigo A, Dean DC. Differential expression and function of members of the zfh- 1 family of zinc finger/homeodomain repressors. Proc Natl Acad Sci USA 2000; 97: 6391-6396.

34. Postigo A, Depp JL, Taylor JJ, Kroll KL.Regulation of Smad signaling through a differential recruitment of coactivators and corepressors by ZEB proteins. EMBO J 2003; 22: 2453-2462.

35. Sanchez-Tillo E, Siles L, de Barrios O, Cuatrecasas M, Vaquero EC et al. Expanding roles of ZEB factors in tumorigenesis and tumor progression. Am J Cancer Res 2011; 1 897-912.
36. De Craene B, Berx G. Regulatory networks defining EMT during cancer initiation and progression. Nat Rev Cancer 2013; 13: 97-110.

37. Hill L, Browne G, Tulchinsky E. ZEB/miR-200 feedback loop: at the crossroads of signal transduction in cancer. Int J Cancer 2013; 132: 745-754.

38. Spaderna S, Schmalhofer O, Wahlbuhl M, Dimmler A, Bauer K, Sultan A et al. The transcriptional repressor ZEB1 promotes metastasis and loss of cell polarity in cancer. Cancer Res 2008; 68: 537-544.

39. Sanchez-Tillo E, Liu Y, de Barrios O, Siles L, Fanlo L, Cuatrecasas M et al. EMT-activating transcription factors in cancer: beyond EMT and tumor invasiveness. Cell Mol Life Sci 2012; 69: 3429-3456

40. Rosenwald A, Wright G, Wiestner A, Chan WC, Connors JM, Campo E et al. The proliferation gene expression signature is a quantitative integrator of oncogenic events that predicts survival in mantle cell lymphoma. Cancer Cell 2003; 3: 185-197.

41. Blenk S, Engelmann JC, Pinkert S, Weniger M, Schultz J, Rosenwald A et al. Explorative data analysis of $\mathrm{MCL}$ reveals gene expression networks implicated in survival and prognosis supported by explorative CGH analysis. BMC Cancer 2008; 8: 106

42. Henderson BR. Nuclear-cytoplasmic shuttling of APC regulates $\beta$-catenin subcellular localization and turnover. Nat Cell Biol 2000; 2: 653-660.

43. Hernandez L, Bea S, Pinyol M, Ott G, Katzenberger T, Rosenwald A et al. CDK4 and MDM2 gene alterations mainly occur in highly proliferative and aggressive mantle cell lymphomas with wild-type INK4a/ARF locus. Cancer Res 2005; 65: 2199-2206.

44. Pinyol M, Bea S, Pla L, Ribrag V, Bosq J, Rosenwald A et al. Inactivation of Rb1 in mantlecell lymphoma detected by nonsense-mediated mRNA decay pathway inhibition and microarray analysis. Blood 2007; 109: 5422-5429.

45. Postigo A. Opposing functions of ZEB proteins in the regulation of the TGF $\beta / B M P$ signaling pathway. EMBO J 2003; 22: 2443-2452.

46. Liu Y, Costantino ME, Montoya-Durango D, Higashi Y, Darling DS. Dean DC.The zinc finger transcription factor ZFHX1A is linked to cell proliferation by Rb-E2F1. Biochem $J$ 2007; 408: 79-85.

47. Liu Y, El-Naggar S, Darling DS, Higashi Y, Dean DC. Zeb1 links epithelial-mesenchymal transition and cellular senescence. Development 2008; 135: 579-588.

48. Räty R, Franssila K, Joensuu H, Teerenhovi L, Elonen E. Ki-67 expression level, histological subtype, and the International Prognostic Index as outcome predictors in mantle cell lymphoma. Eur J Haematol 2002; 69: 11-20.

49. Hartmann E, Fernandez V, Moreno V, Valls J, Hernandez L, Bosch F et al. Five-gene model to predict survival in mantle-cell lymphoma using frozen or formalin-fixed, paraffinembedded tissue. J Clin Oncol 2008; 26: 4966-4972.

50. Martinez A, Bellosillo B, Bosch F, Ferrer A, Marce S, Villamor $\mathrm{N}$ et al. Nuclear survivin expression in mantle cell lymphoma is associated with cell proliferation and survival. $A m \mathrm{~J}$ Pathol 2004; 164: 501-510.

51. Huang Y. Pharmacogenetics/genomics of membrane transporters in cancer chemotherapy. Cancer Metastasis Rev 2007; 26: 183-201.

52. Galimberti S, Nagy B, Benedetti E, Pacini S, Brizzi S, Caracciolo F et al. Evaluation of the MDR1, ABCG2, topoisomerases $\| \alpha$ and GSTpi gene expression in patients affected by aggressive mantle cell lymphoma treated by the R-hyper-CVAD regimen. Leuk Lymphoma 2007; 48: 1502-1509

53. Marce S, Molina-Arcas M, Villamor N, Casado FJ, Campo E, Pastor-Anglada M et al. Expression of human equilibrative nucleoside transporter 1 (hENT1) and its correlation with gemcitabine uptake and cytotoxicity in mantle cell lymphoma. Haematologica 2006; 91: 895-902.

54. Chou TC. Drug combination studies and their synergy quantification using the ChouTalalay method. Cancer Res 2010; 70: 440-446.

55. Rosich L, Xargay-Torrent S, Lopez-Guerra M, Campo E, Colomer D, Roue G. Counteracting autophagy overcomes resistance to everolimus in mantle cell lymphoma. Clin Cancer Res 2012; 18: 5278-5289.

56. Bea S, Salaverria I, Armengol L, Pinyol M, Fernández V, Hartmann EM et al. Uniparental disomies, homozygous deletions, amplifications, and target genes in mantle cell lymphoma revealed by integrative high-resolution whole-genome profiling. Blood 2009; 113: 3059-3069.

57. Riccioni R, Dupuis ML, Bernabei M, Petrucci E, Pasquini L, Mariani G et al. The cancer stem cell selective inhibitor salinomycin is a p-glycoprotein inhibitor. Blood Cells Mol Dis 2010; 45: 86-92.

58. Gurney A, Axelrod F, Bond CJ, Cain J, Chartier C, Donigan L et al. Wnt pathway inhibition via the targeting of Frizzled receptors results in decreased growth and tumorigenicity of human tumors. Proc Natl Acad Sci USA 2012; 109: 11717-11722.

59. Anastas JN, Moon RT. WNT signalling pathways as therapeutic targets in cancer. Nat Rev Cancer 2013; 13: 11-26.

60. Alizadeh A, Eisen M, Davis RE, Ma C, Sabet H, Tran T et al. The lymphochip: a specialized cDNA microarray for the genomic-scale analysis of gene expression in normal and malignant lymphocytes. Cold Spring Harb Symp Quant Biol 1999; 64: 71-78. 